\title{
The Need for Tobacco Dependence Treatment
}

\section{Author:}

Harry A. Lando*

Division of Epidemiology and

Community Health

University of Minnesota

1300 South Second Street,

Suite 300

E-mail: 1ando001@umn.edu

Phone: 612-624-1877

Elizabeth A. Lando-King

Independent Consultant

*Corresponding author
Keywords: Tobacco, tobacco

dependence treatment, accessibility

\section{Abstract}

Tobacco dependence treatment can substantially reduce the huge global death toll from tobacco in the near future. The World Health Organization's Framework Convention on Tobacco Control recognizes the right of dependent tobacco users to receive treatment. Evidence clearly indicates that treatment of tobacco dependence is both effective and cost-effective. Simple advice from a clinician increases quitting and more intense interventions including counseling and/or medication further increase the likelihood of success. Given the devastating impact of tobacco and the reported desire by most tobacco users to quit, it is of particular concern that approximately $95 \%$ of the world's population has little or no access to treatment. Highincome countries are far more likely to offer comprehensive cessation services than are middle- or low-income countries, but even in high-income countries the situation typically is far from ideal especially for traditionally underserved populations. Needed is a sustainable, comprehensive, and affordable approach to delivery of tobacco dependence treatment services. Trained lay interventionists can deliver effective counseling at minimal cost. Telephone support and text messaging can be delivered inexpensively through cell phones. Physicians and other highly regarded professionals can be enlisted as nontobacco role models. Inexpensive medications may be available including generic products and those manufactured locally. In many countries, infrastructure can be put in place to support provision of services through existing healthcare systems. Universal accessibility of effective treatments is both a public health imperative and an ethical and moral obligation. 
The Need for Tobacco

\section{Dependence Treatment}

Tobacco dependence treatment has the potential to significantly reduce the global tobacco death toll in the near future. Quitting smoking has immediate benefits in saving lives. The World Bank estimates that more than 180 million lives could be saved in just the first half of this century by implementing on a global scale what we currently know about treating tobacco dependence (World Bank 1999). Raw and his colleagues (2009) note that worldwide success in tobacco cessation is imperative if we are to attain the goal of $\mathrm{WHO}$ and the UN of achieving a $25 \%$ reduction in premature mortality from noncommunicable diseases by 2025 .

The World Health Organization, in its first internationally binding treaty, the Framework Convention on Tobacco Control (WHO 2005), recognizes the right to treatment in Article 14 of the Convention (Raw et al. 2011). Article 14 states that "Each Party shall develop and disseminate appropriate, comprehensive and integrated guidelines based on scientific evidence and best practices, taking into account national circumstances and priorities, and shall take effective measures to promote cessation of tobacco use and adequate treatment of tobacco dependence." Unfortunately, the potential impact of tobacco dependence treatment is largely unrealized and only $5 \%$ of the world's population has good access to effective treatment (Raw et al. 2009).

\section{Tobacco Dependence Treatment}

\section{is Effective}

It is especially unfortunate that tobacco dependence treatment is not more widely available because we know that treatment is effective and we now have low-cost methods to assist hardcore smokers in quitting. Treating Tobacco Use and Dependence: 2008 Update (Fiore et al. 2008) is an excellent resource that describes evidence-based methods. These methods range from simple clinician advice to intensive specialized programs. 
The tobacco dependence guidelines recommend that all tobacco users be offered cessation assistance and conclude that a combination of counseling and medication is most effective. The guidelines strongly encourage clinician advice and referral. Importantly, tobacco is identified as a chronic disease that can require repeated intervention and multiple quit attempts. Clinicians and health care delivery systems are urged to prioritize identifying and documenting tobacco use status and treatment of every tobacco user seen in a health care setting.

Unfortunately, most smokers continue to rely upon unaided quit attempts. Smokers attempting to quit on their own have approximately a 5\% chance of being abstinent one year later. Use of either counseling or medications can more than double their chances and the combination of both can increase their odds further (Fiore et al. 2009). Even hardcore long-term smokers can quit permanently, although it may take a number of attempts before they are successful.

Tobacco dependence treatment is considered the gold standard of costeffectiveness (Parrott et al. 1998; Guerriero et al. 2013; Gilbert, Pinget, Bovet, 2004). Many routinely applied interventions such as treating hypercholesterolemia and hypertension yield lower return on investment (Fiore et al. 2008). Although more intensive interventions tend to produce better outcomes, even brief advice from a physician can significantly improve quit rates (Aveyard et al. 2012). This could be as simple as a statement that "As your doctor, I believe the most important thing you can do for your health is to quit smoking."

The guidelines also recommend that clinicians should encourage patients who are willing to make a quit attempt to avail themselves of counseling services and medications. Combinations of medications may also be indicated. Thus, one might 
use nicotine patch to maintain a constant (usually relatively low) level of nicotine and nicotine gum or lozenge as needed to combat cravings.

The guidelines note that individual, group, and telephone counseling are effective and that effectiveness increases with treatment intensity. Problem solving/skills training and social support delivered as part of treatment have proven to be effective. Current approved medications have been shown to increase long-term abstinence rates. These include bupropion SR, varenicline, nicotine gum, nicotine inhaler, nicotine lozenge, nicotine nasal spray, and nicotine patch.

Smokers are at substantially elevated risk for multiple life threatening conditions, including lung and multiple other cancers and heart disease including sudden death from heart attack. Smoking related deaths are entirely preventable and all too often these occur in what should be the prime of life (USDHHS 2014).
We see major disparities in smoking patterns. In the US, smoking is now concentrated much more among those who are less educated and lower income. Those who abuse alcohol and other drugs are far more likely to be tobacco dependent as are those who are severely mentally ill (MMWR 2015).

\section{The Current Situation}

Given the devastating impact of smoking and the reported desire by most smokers to quit, it is most unfortunate that approximately $95 \%$ of the world's population has little or no access to treatment. Needed is a broad spectrum of available treatment ranging from simple advice and encouragement to intensive individual and group programs and even inpatient options. Treatment should be readily accessible and accessibility and financial barriers should be minimized to the extent possible. Insurance coverage for cessation treatments is highly recommended and such coverage increases quit rates. Of particular concern 
are continuing smokers who suffer serious medical comorbidities such as diabetes and peripheral artery disease. The combination of diabetes and smoking dramatically elevates risk of coronary artery disease. Those who suffer PAD and who continue to smoke are at far greater risk of dying within five years than are PAD sufferers who are able to quit (Hirsch et al. 1997).

High-income countries including the United States typically offer fairly comprehensive cessation services, although these are not readily accessible to some of the populations in greatest need of these services. There has been resistance in chemical dependency programs and in mental health services to treating smoking due to fears that this could lead to relapse to alcohol or other substances and to worsening of psychiatric problems respectively. It is important to note that individuals diagnosed with schizophrenia, for example, have on average a shorter life expectancy than the general population by fully 25 years (Crump et al. 2013). High rates of smoking are a contributing factor to this huge disparity. Clinicians need to recognize that individuals who are severely mentally ill die from smoking at higher rates and that smoking is itself a potentially life threatening condition.

The situation in low- and middleincome countries (LMICs) is considerably less favorable than in high-income countries. Cessation services often are minimal or even completely lacking. In countries such as China there is a high prevalence of smoking among medical professionals and there are relatively few ex-smoker role models. This increases the challenges of supporting quitting. In India there are a relative handful of urban cessation clinics for a population of over 1 billion people (Varghese et al. 2012). In the US more than half of those who ever smoked are now exsmokers (MMWR 2015). This leads to an environment that is restrictive toward smoking and that tends to make quitting normative (although this is less true for some high-risk populations 
such as blue collar workers in some industries that have high prevalence of smoking).

The relative lack of exsmoker role models (exsmokers comprise no more than $5 \%$ to $10 \%$ of ever smokers in many low- and middle-income countries, Gilbert et al. 2004) further increases the challenges in many low- or middleincome countries. Whereas the prevalence of smoking is declining in most highincome countries, it is increasing elsewhere as the tobacco industry increasingly targets LMICs (Abdullah, Husten 2004). An additional challenge noted by Abdullah and Husten is far less intention to quit in low- or middle-income countries (China 14-16\%, India 31\% versus over $70 \%$ in many high-income countries).

Indonesia is sometimes described as the smokers' paradise. In our work there, we surveyed medical doctors. Most of the doctors surveyed indicated that it was safe to smoke up to 10 cigarettes per day
(Nichter 2006). Given this misconception on the part of medical professionals, it is not surprising that lay people have limited knowledge and awareness of tobacco harms. Gaziano (2007) notes that there are more than one billion smokers worldwide and $80 \%$ reside in low- or middle-income countries. Nearly one-third of all tobacco users in LMICs die from cardiovascular disease and yet they simply may not be aware of these risks.

\section{Toward Universal Tobacco}

\section{Dependence Treatment}

Needed is a comprehensive approach to delivery of tobacco dependence treatment services. We would argue that it is unethical to continue to raise prices and to restrict smoking without also offering treatment to dependent tobacco users.

Even in low-income countries it should be possible to engage medical professionals to provide routine advice. Also, we have had success in training lay people to conduct effective group 
programs (Lando, 1987). Lay interventionists could be an important resource in low- as well as in middle- and high-income countries. Although medications including nicotine replacement, bupropion, and varenicline tend to be expensive, there may be alternatives that are affordable even in low-income countries. Cytisine is one possibility. There is good evidence for cytisine's efficacy and it is far less costly than other medications (Walker et al. 2016).

Medications have been shown to be cost-effective in low-income countries and reducing out of pocket cost can increase use and number of successful quitters (Abdullah, Husten 2004). Governments might be able to negotiate to reduce price. Drugs can be manufactured locallyprices of generic bupropion and nicotine gum manufactured in India could be one eighth of the US price (Gilbert et al. 2004).

Infrastructure should be in place to support provision of tobacco dependence treatment. Pine-Abata et al. (2013) point to several key components including: a focal point or national coordinating mechanism, a national cessation strategy, national treatment guidelines, focus on health care workers, national training standards, use of existing infrastructure, mandatory inclusion of tobacco use in medical notes, and sustainable funding. It is not clear, however, that each country would need its own independent guidelines and training standards. Rather it should be possible to adapt programs based on existing guidelines.

These authors also call for several components in national cessation support systems including: mass communication and education to encourage cessation, brief advice in all health care systems, quitlines, access to affordable medications, and specialized tobacco dependence treatment services. It also should be possible to take advantage of social media in texting, providing tips and links to resources, and in providing support and encouragement. Of the 121 countries 
surveyed, only 9 (30\%) of lower-middle and $2(11 \%)$ of low-income countries had guidelines for tobacco dependence treatment (Pina-Abata et al. 2013).

The World Health Organization Commission on Macroeconomics and Health includes smoking on a short list of specific conditions that should be a priority in low-income countries to “...save millions of lives, reduce poverty, spur economic development, and promote global security." We would argue that, especially for individuals with co-morbid conditions, tobacco dependence treatment including the possibility of intensive specialized treatment should be a priority. In India and Indonesia, for example, TB is prevalent. Those who suffer TB and who continue to smoke have a significantly worse clinical course (Yen et al. 2014). There is evidence that HIV+ smokers also fare poorly (Van Zyl Smit et al 2010).

We advocate for a comprehensive program of tobacco dependence treatment offerings in all countries, recognizing the many challenges involved. Ideally, revenue from increased taxation on tobacco products could in part go to support of cessation services. Currently, governments spend a tiny fraction of tobacco revenue on tobacco control programs of any type. South Korea added a surcharge and progressively increasing tax on cigarettes with funds directed to tobacco control (Beaglehole et al. 2012). Even with minimal resources, however, health systems can be engaged and tobacco users can be identified and given advice and encouragement to quit. With increasing penetration of cell phones and social media, supportive messages and counseling can be delivered at low cost. Lay people can be trained as effective interventionists (Lando, 1987; Muramoto et al. 2014). Medications can be made available at low cost through local manufacture as well as through possible distribution of inexpensive drugs such as cytisine.

As an early entry point, one can engage highly respected opinion leaders 
including physicians and teachers as role models for cessation. This was a major focus of our previous work in India and Indonesia (Nichter 2006). In Bihar, India, we were successful in using teachers as role models and in encouraging teachers to quit tobacco use (Sorensen et al. 2013). If physicians in particular have high smoking rates as we observed in India and Indonesia, this makes it more challenging to reach the population as a whole. A priority should be placed upon both reducing smoking prevalence among physicians as well as other highly educated professionals and on engaging these professionals as advocates for quitting. Additional possibilities include recruiting religious leaders such as monks in Thailand and promoting quitting at auspicious times such as during Ramadan in Muslim countries. We believe that through these initiatives we can speed progress through the stages of the tobacco epidemic (Lopez et al. 1994; Thun et al. 2012).

\section{$\underline{4 . \text { Conclusion }}$}

Tobacco dependence has a devastating impact. Current estimates are that there will be 1 billion tobacco related deaths in the $21^{\text {st }}$ century (Jha \& Peto 2014). Peto has noted that smoking presents a unique combination of lethality and neglect. Reducing smoking prevalence has the greatest short- to intermediate term potential to substantially reduce the anticipated death toll. Effective tobacco dependence treatments are available and can be offered at a low cost. Universal accessibility of such treatments is not only a public health imperative but also an ethical and moral obligation. 


\section{References}

Abdullah, A., Husten, C. (2004). Promotion of smoking cessation in developing countries: A framework for urgent public health interventions. Thorax, 59:623-630.

Aveyard, P., Begh., R., Parsons, A., West., R. (2012). Brief opportunistic smoking cessation interventions: A systematic review and meta-analysis to compare advice to quit and offere of assistance. Addiction, 107(6), 1066-73. doi: 10.1111/j.1360-0443.2011.03770.x.

Beaglehole, R., Epping-Jordan, J., Patel, V., Chopra, M., Ebrahim, D., Kidd, M., Haines, A. (2008). Improving the prevention and management of chronic disease in low-income and middleincome countries: A priority for primary health care. Lancet, 372(9642):940-949. doi: http://dx.doi.org/10.1016/S01406736(08)61404-X

Crump, C., Winkleby, M. A., Sundquist, K., \& Sundquist, J. (2013). Comorbidities and mortality in persons with schizophrenia: a Swedish national cohort study. American Journal of Psychiatry, 170(3), 324-333. doi: 10.1176/appi.ajp.2012.12050599
Fiore, M., Jaen, C., Baker, T. et al. (2008). Treating Tobacco Use and Dependence: 2008 Update. Clinical Practice Guideline: Rockville, MD: U.S. Department of Health and Human Services. Public Health Service. Available at: http://bphc.hrsa.gov/buckets/treatingtoba cco.pdf

Gaziano, T. (2007). Reducing the growing burden of cardiovascular disease in the developing world. Health Affairs, 26(1):13-24. doi:10.1377/hlthaff.26.1.13

Gilbert, A., Pinget, C., Bovet, P. (2004). The cost effectiveness of pharmacological smoking cessation therapies in developing countries: A case study in the Seychelles. Tobacco Control, 13:190-195.

Guerriero, C., Cairns, J., Roberts, I., Rodgers, A., Whitaker, R., Free, C. (2013). The cost-effectiveness of smoking cessation support delivered by mobile phone text messaging: Txt2stop. European Journal of Health Economics, 14:789-797. doi: 10.1007/s10198-0120424-5. 
Hirsch, A., Treat-Jacobson, D., Lando, H., Hatsukami, D. (1997). The role of tobacco cessation, antiplatelet and lipidlowering therapies in the treatment of peripheral arterial disease. Vascular Medicine, 2:243-251.

Jamal, A., Homa, D. M., O'Connor, E., Babb, S. D., Caraballo, R. S., Singh, T., .. \& King, B. A. (2015). Current cigarette smoking among adults-United States, 2005-2014. MMWR Morb Mortal Wkly Rep, 64(44), 1233-1240. doi:10.15585/mmwr.mm6444a2

Jha, P., Peto, R. (2014). Global effects of smoking, of quitting, and of taxing tobacco. New England Journal of Medicine, 370(1), 60-68. doi: 10.1056/NEJMra1308383

Lando, H. (1987). Lay facilitators as effective smoking cessation counselors. Addictive Behaviors, 12:69-72.

Lopez, A., Collishaw, N., Pina, T. (1994). A descriptive model of the cigarette epidemic in developed countries. Tobacco Control, 3:242-247.

Muramoto, M., Hall, J., Nichter, M., Nichter, M., Aickin, M., Connolly, T., Matthews, E., Campbell, J., Lando, H. (2014) Activating lay influencers to promote tobacco cessation. American Journal of Health Behavior, 38(3):392403. doi: 10.5993/AJHB.38.3.8.

Nichter, M. (2006). Introducing tobacco cessation in developing countries: An overview of Project Quit Tobacco International. Tobacco Control, 15(Suppl 1):i12-i17. doi: 10.1136/tc.2005.014704

Parrott, S., Godfrey, C., Raw, M., West, R., McNeill, A. (1998). Guidance for commissioners on the cost effectiveness of smoking cessation interventions. Thorax, 53:S1-S38.

Pine-Abata, H., McNeill, A., Raw, M., Bitton, A., Rigotti, N., Murray, R. (2013). A survey of tobacco dependence treatment guidelines in 121 countries. Addiction, 108:1470-1475. doi: 10.1111/add. 12158

Raw, M. (2011). Framework Convention on Tobacco Control (FCTC) Article 14 guidelines: A new era for tobacco dependence treatment. Addiction, 106, 2055-2057. doi:10.1111/j.1360-0443.2011.03536.x

Raw, M., Glynn, T., Munzer, A., Billo, N., Mortara, I., Bianco, E. (2009). Editorial: Tobacco dependence 
treatment and the Framework Convention on Tobacco Control. Addiction, 104(4), 507-509.

Sorensen, G., Pednekar, M., Sinha, D., Stoddard, A., Nagler, E., Aghi, M., Lando, H., Viswanath, K., Pawar, P., Gupta, P.(2013). Effects of a tobacco control intervention for teachers in India: Results of the Bihar School Teachers Study. American Journal of Public Health, 103(11):2035-2040. doi: 10.2105/AJPH.2013.301303.

Thun, M., Peto, R., Boreham, J., Lopez, A. (2012). Stages of the cigarette epidemic on entering its second century. Tobacco Control, 21:96-101. doi:10.1136/tobaccocontrol-2011050294

U.S. Department of Health and Human Services. (2014). The Health Consequences of Smoking - 50 Years of Progress: A Report of the Surgeon General. Atlanta, GA: U.S. Department of Health and Human Services, Centers for Disease Control and Prevention, National Center for Chronic Disease Prevention and Health Promotion, Office on Smoking and Health.

Van Zyl Smit, R.,Pai, M., Yew, P., Leung, C., Zumia, A., Bateman, E.,
Dheda, K. (2010). Global lung health: the colliding epidemics of tuberculosis, tobacco smoking, HIV and COPD. European Respiratory Journal, 35(1):27-33. doi:

10.1183/09031936.00072909

Varghese, C., Kaur, J., Desai, N., Murthy, P., Malhotra, S., Subbakrishna, D., Prasad, V., Munish, V. (2012). Initiating tobacco cessation services in India: Challenges and opportunities. WHO South-East Asia Journal of Public Health, 1(2):159-168.

Walker, N., Bullen, C., Barnes, J., McRobbie, H., Tutka, P., Raw, M., Etter, J., Siddiqi, K., Courtney, R., CastaldelliMaia, J., Selby, P., Sheridan, J., Rigotti, N. (2016). Getting cytisine licensed for use world-wide: A call to action. Addiction, 111:1895-1898. doi: 10.1111/add.13464

World Bank. 1999. Curbing the epidemic - governments and the economics of tobacco control. Development in practice. Washington DC; World Bank. http://documents.worldbank.org/curated/ en/914041468176678949/Curbing-theepidemic-governments-and-theeconomics-of-tobacco-control 
World Health Organization (WHO). (2003). WHO Framework Convention on Tobacco Control. Available at:http://apps.who.int/iris/bitstream/1066 5/42811/1/9241591013.pdf

Yen, Y., Yen, M., Lin, Y., Shih, H, Li, L, Chou, P., Deng, C. (2014). Smoking increases risk of recurrence after successful anti-tuberculosis treatment: A population-based study. International Journal of Tuberculosis and Lung Disease, 18(4):492-498. doi: 10.5588/ijtld.13.0694 